\title{
The luck argument against event-causal libertarianism: It is here to stay
}

\author{
Markus E. Schlosser, University of Groningen, $\underline{\text { m.e.schlosser@rug.nl }}$ \\ Forthcoming in Philosophical Studies
}

This is the author's copy (which may differ from the final print version in minor details)

\begin{abstract}
The luck argument raises a serious challenge for libertarianism about free will. In broad outline, if an action is undetermined, then it appears to be a matter of luck whether or not one performs it. And if it is a matter of luck whether or not one performs an action, then it seems that the action is not performed with free will. This argument is most effective against event-causal accounts of libertarianism. Recently, Christopher Franklin (2011, this journal) has defended event-causal libertarianism against four formulations of the luck argument. I will argue that three of Franklin's responses are unsuccessful and that there are important versions of the luck challenge that his defense has left unaddressed.
\end{abstract}

Keywords: Free will, incompatibilism, event-causal libertarianism, luck argument, causal theory of action

\section{Introduction}

Libertarianism about free will faces many challenges. One of the most serious problems stems from considerations concerning the kind of luck that appears to be inherent to choices that are genuinely undetermined. A closely related challenge stems from what van Inwagen called the "Mind argument" (1983, p. 126-150). Both objections purport to show that the kind of indeterminism that is required by libertarianism is incompatible with the kind of agency that is required for free will. In a recent article, Christopher Franklin (2011, this journal) has defended an event-causal account of libertarianism against four versions of the luck argument and against the Mind argument. Franklin's contribution provides valuable insights, and I found his reply to the Mind argument persuasive. However, I think that his defense against the luck argument is less than convincing, and I will argue that three of the four responses are unsuccessful. I will argue, in particular, that two of his responses address only one particular interpretation, leaving other versions of the challenge untouched, and that one response is entirely unconvincing. 


\section{Libertarianism}

According to libertarianism, we have free will and having free will is incompatible with the thesis of (causal or nomological) determinism. Determinism could be false in indefinitely many ways. Most libertarians, including Franklin, agree that we have free will only if some of our choices are undetermined in the sense that the making of the choice is an undetermined mental action. Let us therefore assume that, according to libertarianism, the indeterminism required for free will must be located at choices. Further, I shall focus here on event-causal accounts of traditional libertarianism, primarily because this is the variety of libertarianism defended by Franklin. ${ }^{1}$ I should note, however, that there are independent reasons for this focus. First, it makes sense to focus on event-causal libertarianism, simply because this version of libertarianism has been the primary target of the luck argument (see, for instance, Mele 1999; Haji 1999 and 2001; Pereboom 2001; Clarke 2003). Second, it is widely agreed that the event-causal theory of action provides the best account of human agency, whereas alternative agent-causal and non-causal theories are widely rejected (for more on this see Schlosser 2008 and 2010). Given this, it is of particular interest to see whether an event-causal account can explain how choosing and acting with free will works.

\section{A preliminary statement of the luck argument}

According to Franklin, the following two claims capture the core of the luck argument, providing a preliminary statement of the challenge (2011, p. 201):

(P1) If an action (or choice) is undetermined, then it is a matter of luck.

(P2) If an action (or choice) is a matter of luck, then it is not free.

If this argument can be substantiated and defended, it shows that the very indeterminacy required by libertarianism undermines freedom. In other words, if sound, the luck argument shows that libertarianism is incoherent. This preliminary statement of the argument leaves the central notion of luck undefined. This is why, I take it, that Franklin responded only to more specific formulations of the argument that make the challenge more precise.

\footnotetext{
${ }^{1}$ Roughly, event-causal accounts can be contrasted with agent-causal and non-causal accounts. Traditional libertarianism can be distinguished from source libertarianism, where the former requires, very roughly, the ability to do otherwise and the latter that one is the source of one's choices.
} 


\section{Specific statements}

Franklin distinguished between four specific statements of the luck argument: the HumeHobbart formulation, the ensurance formulation, the rollback formulation, and explanatory formulations. The response to the first is persuasive and quite straightforward (ibid., pp. 208-209). The Hume-Hobbart formulation presupposes that causation is necessarily deterministic. This entails that undetermined events are entirely uncaused, and it can be argued that their occurrence is therefore just a matter of luck. However, it is now widely agreed that causation may well be probabilistic. This observation alone is sufficient to rebut this formulation. Let us turn, then, to the other three formulations.

\subsection{The ensurance formulation}

According to Franklin, the ensurance formulation captures best what most philosophers have in mind when they claim that indeterminism undermines or diminishes control. The core idea here is that if the performance of an action $A$ is undetermined, then the agent could not have ensured to do A rather than otherwise (ibid., p. 209). Given this, one can construct a luck argument on the basis of the following two premises (which replace P1 from the preliminary formulation):

(E1) Undetermined actions (or choices) are not ensured.

(E2) If an action (or choice) is not ensured, then it is a matter of luck.

As Franklin notes, it is quite unclear what it is to ensure an action (or choice). ${ }^{2}$ In order to address this issue, he turns to Ishtiyaque Haji's work (1999 and 2001). According to Haji, an agent $S$ can ensure that she performs an action $A$ only if $S$ has antecedent control over $A$. And $S$ has antecedent control over $A$ if she can "see to it" that she does $A$ rather than something else. This, however, appears to be equally uninformative, and so Franklin proceeds by offering the following reconstruction of what he thinks that Haji has in mind (see p. 210):

\footnotetext{
${ }^{2}$ In what follows, some claims will be formulated only in terms of action, others will be formulated only in terms of choice, for ease of presentation. As mentioned, I assume, as it is common in this debate, that choices are mental actions, and I shall assume that one may in all instances substitute "making a choice" for "performance of an action", and vice versa.
} 
(AC) $S$ has antecedent control over an action $A_{2}$ at $t_{2}$ just in case $S$ has the power to do $A_{1}$ at $t_{1}$ and, if $S \operatorname{did} A_{1}$ at $t_{1}$, then $A_{1}$ would deterministically bring about $A_{2}$ at $t_{2}$.

On the basis of this reconstruction, Franklin then rejects E1 and identifies a dilemma for E2. I shall not attempt to reproduce these arguments - which I find convincing-, because they are, in my opinion, based on an implausible interpretation of the initial statement of the ensurance argument. In particular, I am not concerned by Franklin's objection to the interpretation of E1 and E2 in terms of AC, because the appeal to antecedent control strikes me as unpromising and implausible to begin with.

It is only plausible to suggest that ensurance is a matter of control. However, it is unpromising to explain ensurance in terms of antecedent control, because any appeal to the possession or exercise of antecedent control raises as many questions as it answers. What does the possession or exercise of this antecedent control consist in? How can the agent ensure to exercise this antecedent control in one way rather than another? And so on.

Moreover, there is, to my mind, something deeply misguided about the suggestion that free will requires a kind of control that the agent can exercise before making a free choice. It is far more natural to think that the kind of control required for free will is exercised by or in making a choice. In particular, exercising the required kind of control is not something that one does before making a choice, and it is not something that one does in addition to making a choice. This, in any case, is how one should think about control within an event-causal framework. According to event-causal theories of action, some events are actions in virtue of their causal history: an event is an action if it is caused by the right mental states in the right (that is, non-deviant) way. The right mental states are states that rationalize the action (such as desires, beliefs, and intentions) - let us call them reasonstates. On this view, then, an agent's exercise of control consists in non-deviant causation by reason-states (for more on this see Schlosser 2008 and 2010). Interestingly, Franklin would seem to agree when he says, in his response to the Mind argument, that an "agent's exercising control over some action $\varphi$ is not something she does in addition to $\varphi$-ing" (ibid., p. 227). Given all this, we should reject an interpretation of the ensurance formulation in terms of antecedent control. But once we reject this interpretation, the initial statement of the ensurance formulation remains unchallenged, as Franklin's response addresses only the interpretation in terms of antecedent control (in particular, AC). 
This, however, brings us back to the question of how the notion of ensurance is to be interpreted. Recall, first, the core idea behind the ensurance formulation: if an action $A$ is undetermined, then the agent cannot ensure to do A rather than to do otherwise (Franklin 2011, p. 209). Second, we noted that ensurance is a kind of control. As we are concerned here with the event-causal approach to free will, it would seem appropriate to construe ensurance in terms of the event-causal account of control.

Given this, we may construe ensurance as follows: $S$ 's choice to do $A$ is ensured if the non-deviant causation of this choice by $S$ 's reason-states constitutes the power or control over whether to do $A$ rather than to do otherwise - the power or control to select which alternative to pursue, as I shall say. However, now the problem is that, if the choice is undetermined, then non-deviant causation by the agent's reason-states cannot constitute the control to select which option to pursue, as the agent's reason-states can only bias one choice of action over another. Let me explain.

Nothing in the event-causal account requires that the causation must be deterministic: control may consist in non-deviant probabilistic causation by reason-states. Consider an agent $S$ who deliberates about whether to pursue the action $A$ or $B$ and whose reason-states, $R$, support both $A$-ing and $B$-ing to some degree. Further, suppose that having $R$ raises the probability of both $S$ 's choosing to $A$ and $S$ 's choosing to $B$ to 0.5 . According to the eventcausal theory, $S$ exercises control if having $R$ non-deviantly causes $S$ 's choice to $A$ and $S$ exercises control if having $R$ non-deviantly causes $S$ 's choice to $B$. However, given that $S$ 's control consists only in the non-deviant causation by $S$ 's reason-states, $S$ appears to have no control over which action to choose - in particular, $S$ appears to have no control over whether to choose to $A$ rather than $B$. What if the probability distribution is uneven? Suppose, for instance, that $R$ raises the probability of choosing to $A$ to 0.8 and the probability of choosing to $B$ only to 0.2 . In this case, we might say that $S$ has some control over whether to choose to $A$ rather than to $B$, in the sense that $S$ 's reason-states bias $S$ to choose to $A$ rather than $B$. Moreover, we might say that $S$ has more control than in a scenario in which $R$ raises the probability of choosing to $A$ to, say, 0.65 . However, even if that is correct, it still seems that $S$ lacks the kind of control that is, intuitively, required for choosing with free will. In none of the outlined scenarios does $S$ have the power or control to select which alternative to pursue. In the first scenario, $S$ has no control over whether to 
choose to $A$ rather than $B$ (or to $B$ rather than $A$ ), and in the second and third scenario, $S$ 's reason-states merely bias one choice over the other.

Given all this, and given E2, we can conclude that undetermined choices are a matter of luck, because they are not ensured in the sense just explained. Franklin's response to the interpretation in terms of antecedent control does not help here, simply because the proposed event-causal interpretation of the ensurance formulation does not appeal to the notion of antecedent control at all.

One might object here that $S$ has all the control that is needed for free will. I very much doubt that a kind of control that merely biases one choice over the other is sufficient for free will, but others might disagree. However, if one thinks that $S$ has the required kind of control, then one is not a traditional libertarian. Traditional libertarians have always argued that compatibilism is objectionable not only because it does not secure metaphysically open alternatives, but also because it does not endow agents with sufficient control (see, for instance, Pereboom 2001, p. 39; Clarke 2003, p. 133; Kane 2007, p. 176; Franklin 2011, p. 202). On an event-causal account, $S$ 's control consists in the non-deviant

causation by $S$ 's reason-states. Agents can have this kind of control in a deterministic world. Further, the biasing of choices does not require genuine indeterminism. We may assume, for instance, that the probabilities of $S$ 's choosing to $A$ and $S$ 's choosing to $B$, given $S$ 's reason-states, are merely statistical, not objective. Accordingly, $S$ 's reason-states may also be said to bias one choice over another in a deterministic world. Given this, $S$ does not have the kind of control required by traditional libertarianism, because $S$ 's control does not go beyond the kind of control that agents can have in a deterministic world.

\subsection{The rollback formulation}

This argument is due to van Inwagen (2000), and it is based on the following thought experiment. Consider Alice, who decided to tell the truth on a certain matter after seriously considering both telling the truth and telling a lie. Suppose that libertarianism is true and that Alice's choice was free and therefore undetermined. Suppose, then, that after Alice made her choice the entire universe was "rolled back" (by God, perhaps) to the moment before Alice decided to tell the truth and then left to unfold again. Then imagine that this happens a thousand times, and that after 726 reruns Alice told the truth in about half of the 
cases and that she told a lie in the remaining cases. Given this, we face the "inescapable impression", according to van Inwagen, that what will happen in the 727th rerun will be a "matter of chance" in the "strictest sense imaginable" (2000, p.15). On the basis of this, van Inwagen raises the following questions:

If she was faced with telling the truth and lying, and it was a mere matter of chance which of these things she did, how can we say that - and this is essential to the act's being free- - she was able to tell the truth and able to lie? How could anyone be able to determine the outcome of a process when it is a matter of objective, ground-floor chance?" (ibid., pp. 15-16)

These questions are of course rhetorical, because the thought experiment is supposed to evoke the intuition that Alice is neither able to tell the truth nor able to tell a lie. Van Inwagen presents this argument as an "intuitive version" of what he calls the Mind argument (ibid., p.16). Despite this, Franklin interprets the challenge as a formulation of the luck argument, suggesting that luck is here interpreted in terms of ("ground-floor") chance, whereby an event is a matter of chance just in case the objective probability of its occurrence is less than 1 (and greater than 0). Following Franklin, we can reconstruct the argument as follows (2011, p. 216):

(R1) If a choice is undetermined, then it is a matter of luck ("ground-floor chance"). (R2) If the occurrence of an event $E$ (at t) is a matter of luck, then no one is able to bring about or prevent $E$ (at $\mathrm{t})$.

Franklin's response to this argument comes in two steps. First, he rejects van Inwagen's argument for R2 (which is based on considerations concerning our ability to make promises). Then he proposes and defends an independent account of abilities, according to which Alice is able to tell the truth and able to tell a lie. I found this part of Franklin's response convincing. But, as before, I do not think that this puts the challenge to rest. I was persuaded by Franklin's response to the argument for R2, and I shall not reproduce this response here. Further, I find the proposed account of abilities attractive and promising. Very roughly, the basic idea here is the following (ibid., p. 218): an agent $S$ is able to $A$ (at $t$ ) if there is a sufficiently large set of close possible worlds in which $S$ performs $A$ (at $t$ ). Given an account along these lines, Alice has both the ability to tell the 
truth and the ability to tell a lie. So, I am happy to grant that the rollback argument does not show that an agent lacks the ability to $A$, if the performance of $A$ is undetermined. However, this does not put the challenge to rest, because the rollback scenario can be used to evoke another luck challenge.

Let us assume, for the sake of argument, that Alice is able to tell the truth and that she is able to tell a lie. Is that sufficient for free will? Does it exclude luck and does it secure the right degree or kind of control? I think that the answers to these questions are clearly negative, for it seems that Alice lacks the power or control to select what to do: even though she has the ability to tell the truth and the ability to lie, she does not seem to have the power or control to choose one alternative rather than the other. This, in turn, suggests that her choice is still a matter of luck (or chance), in the sense that it is still a matter of luck (or chance) which alternative she will choose. Van Inwagen seems to come close to raising this challenge when he suggests that no one is "able to determine the outcome of a process when it is a matter of objective, ground-floor chance" (2000, p.16; emphasis added). We assume, now, that Alice has the ability to tell the truth and the ability to lie. This seems insufficient, however, because it seems to remain a matter of luck (or chance) whether Alice exercises her abilities in one way rather than another. This is just another way of saying that Alice lacks the power or control to exercise either one of the two abilities such that she can select which alternative to pursue. Given this, Franklin's response is insufficient, because it shows only that Alice may possess the relevant act-abilities (that is, the ability to tell the truth and the ability to lie).

We granted that Franklin's response to van Inwagen's rollback challenge is successful. However, we have seen that the rollback scenario gives rise to another luck challenge, because it remains a matter of luck (and insufficient control) which alternative Alice will choose. This challenge remains unaddressed.

\subsection{Explanatory formulations}

The main idea here is to define luck in terms of the unavailability of a certain kind of explanation - namely, a contrastive explanation of why the agent chooses to do one thing rather than another. The most elaborate and forceful statement of this argument has been 
put forward by Alfred Mele (2006), and Franklin (2011, p. 220) has provided the following helpful reconstruction of the main argument:

(1) If $S$ performs an undetermined action $A$ at $t$ in the world $W$ and there is some possible world $W^{*}$ that shares the same laws and past as $W$ up to $t$, but in which $S$ performs $B$, then there is nothing that accounts for the difference between $W$ in which $S A$-ed and $W^{*}$ in which $S B$-ed.

(2) If nothing accounts for this difference, then the difference is just a matter of luck.

(3) If the difference is just a matter of luck, then it is partly a matter of luck that $S A$-ed in $W$ and partly a matter of luck that $S B$-ed in $W^{*}$.

(4) If an action is partly a matter of luck, then the action is not free.

(5) Therefore, if an action is undetermined, then it is not free. ${ }^{3}$

Franklin accepts premise 4, saying that it is "hard to believe that an action that is partly a matter of luck could also be free" (ibid., pp. 220). However, he makes it clear that 4 is acceptable only on the condition that it refers to a notion of luck that is intimately connected to control, such that the presence of luck would undermine or diminish control (ibid. p. 221). According to Franklin, the problem with the stated argument is that it violates this condition. For this argument, Mele defined luck as the absence of a contrastive explanation, which enables the inference from 1 to 3 . Franklin thinks that this is fallacious, as the absence of a contrastive explanation does not entail (or tightly track) the absence or diminution of control. So, the argument fails, because it is not clear that luck undermines free will, if luck does not entail (or tightly track) the absence or diminution of control. The crucial question, then, is whether or not the absence of a contrastive explanation does entail (or tightly track) the absence or diminution of control. Franklin's argument for the claim that it does not goes as follows.

It is widely agreed, Franklin notes (ibid.), that explanations are subject to various epistemic and pragmatic conditions. Following some of Hitchcock's (1999) remarks on this, Franklin says that, due to pragmatic constraints, one cannot provide a person with a contrastive explanation if that person already knows all the relevant facts about the matter. More generally, whether or not one can provide a particular person with a certain

\footnotetext{
${ }^{3}$ Again, one may substitute "(making) a choice" for "(performance of) an action" in this argument. See note 2.
} 
explanation depends on what that person already knows. In contrast, conditions of this kind do clearly not apply to control: whether or not a certain agent possesses or exercises a certain kind of control appears to be entirely independent from pragmatic and epistemic conditions. This shows, according to Franklin, that the availability of an explanation cannot tightly track control. In particular, the lack of a contrastive explanation cannot tightly track a lack of control.

My response is twofold. First, the argument from the pragmatic and epistemic conditions is far from decisive. What the proponents of the explanatory formulation have in mind, it seems, is the question of whether there is a certain type of explanation available, and not whether it would be pragmatically or epistemically appropriate to give a certain explanation to a certain individual. As mentioned, Franklin follows Hitchcock in outlining some of the pragmatic and epistemic conditions on explanation. However, what is important here, and what Franklin does not mention, is that Hitchcock distinguishes between explanations that are merely technically correct, and explanations that are also pragmatically adequate (1999, p. 588). In particular, he suggests that if we provide someone with an explanation without providing this individual with new information, we may give an explanation that is technically correct but pragmatically defective (ibid., pp. 598-599, for instance). Franklin focuses on the conditions for the pragmatic adequacy of explanations, and he observes that control is not subject to such conditions. But proponents of the explanatory formulation are concerned only with the availability of explanations that are, in Hitchcock's terminology, technically correct. If we take this into account, Franklin's objection appears to be beside the point. The objection highlights only the point that pragmatic and epistemic correctness does not track control. It does not follow, and Franklin has done nothing to show, that there cannot be technically correct explanations that track control.

Second, it is certainly true that not all explanations track control. But there is also good and independent reason to think that there are explanations that track control. Consider again the event-causal theory. On this view, control consist in non-deviant causation by mental states that provide rationalizing or reason explanations. That is just to say that, on this view, the availability of the right type of explanation tracks control tightly. That is sufficient to show that Franklin's general claim does not hold: there are types of 
explanation that do track control. Further, as Franklin himself notes, there is a contrastive explanation of why an agent decided to $A$ rather than $B$, if the agent's reason-states raised the probability of choosing to $A$ higher than they raised the probability of choosing to $B$ (2011, pp. 222-23). In such cases, the agent can be said to have some degree of control over whether to $A$ rather than $B$, which the agent would lack if the probabilities were even (or if the reason-states raised the probability of choosing to $B$ higher than they raised the probability of choosing to $A$ ). This shows that there are also contrastive reason explanations that track this kind of contrastive control.

Let us turn then to the final argument that needs to be addressed: Franklin's objection to premise 1 . The argument here is that it is possible to explain the difference between $W$ (in which $S A$-ed) and $W^{*}$ (in which $S B$-ed), if $S$ 's reason-states raised the probabilities in the right way. To illustrate, suppose that $S$ 's having the reason-states $R$ raised the probability of $S$ 's choosing to $A$ to 0.8 and the probability of choosing to $B$ to 0.2. Arguably, this provides an explanation of why $S$ decided to $A$ rather than $B$ (in $W$ ), and it shows that there is something wrong with premise 1: if $R$ raised the probability of $A$-ing higher than the probability of $B$-ing, then there is something that accounts for the difference between $W$ in which $S A$-ed and $W^{*}$ in which $S B$-ed. However, once again, this does not put the challenge to rest.

In order to see this, let us reflect on the possibility that the agent might have chosen to $B$. In a footnote, Franklin acknowledges that the contrastive fact that $S$ decided to $A$ rather than $B$ can be explained only if $R$ raised the probability of $S$ 's choosing to $A$ higher than it raised the probability of $S$ 's choosing to $B$ (p. 223, note 32 ). This means that whether or not a contrastive explanation is available depends on whether or not the agent chooses the alternative that is rendered most probable by $R$. But nothing guarantees this. Given that the choice was undetermined, $S$ might have chosen to $B$. And had $S$ chosen to $B$, there would have been no contrastive explanation (of why $S$ chose to $B$ rather than $A$ ). In other words, $W^{*}$ might have turned out to be the actual world, and there is no contrastive explanation of why $S B$-ed rather than $A$-ed in $W^{*}$, because $R$ did not raise the probability of $S$ 's choosing to $B$ higher than it raised the probability of $S$ 's choosing to $A$.

Franklin is right to point out that there is a contrastive explanation if $S$ chooses to $A$. But as nothing guarantees this, it remains partly a matter of luck whether or not $S$ chooses 
the alternative that is rendered most probable by the reason-states, and so it remains partly a matter of luck whether or not there is a contrastive explanation of $S$ 's choice of action. Given, furthermore, that the availability of this contrastive explanation tracks a kind of contrastive control (as I have argued above), it remains partly a matter of luck whether or not $S$ has this kind of control. We face, yet again, a luck challenge. This challenge differs from the explanatory formulation discussed by Franklin, but it does turn on the availability of a contrastive explanation, and it raises a clear and serious challenge for event-causal libertarianism.

\section{Objection and reply}

I have claimed that the luck argument shows, in one way or another, that the agent lacks the power or control to select which alternative to pursue. But I have not defined this notion, and so one might object that it is not clear what the challenge consists in, as it is not clear what kind of power or control the agent is supposed to lack.

There are a couple of closely related points to be made here. As pointed out, traditional libertarians hold that having free will consists in having a kind of control that cannot be had by agents in a deterministic world. Since neither non-deviant causation by reason-states nor the biasing of choices by reason-states requires genuine indeterminism, it seems that there is something missing in the event-causal account of libertarianism. Intuitively, what seems to be missing is the power or control over which alternative to pursue - the power or control to select one alternative rather than another. I think it is clear enough what it means to say that an agent has (or lacks) the power or control to select one alternative rather than another. In other words, I do not think that this notion is in need of definition. What is needed, rather, is an account of what having this kind of control consists in - an account of how this kind of control works. That, however, is a task for libertarians, not for proponents of the luck argument. In fact, proponents of the luck argument could not coherently give an account of this kind of control under the assumption that free choices are undetermined. They argue, in effect, that it is impossible to have this kind of control over undetermined choices. Given this, it would clearly be unreasonable to demand an account of the missing kind of control from the proponents of the luck argument. It is not 
unreasonable, however, to demand this from libertarians, as they think that we have this kind of control over undetermined choices.

\section{Conclusion}

To summarize, Franklin's response to the ensurance formulation addresses only the particular and implausible interpretation in terms of antecedent control; the response to the rollback formulation addresses only the worry that indeterminism is incompatible with the possession of act-abilities; and the response to the explanatory formulation shows only that it is a mistake to hold that nothing can account for the difference between the relevant possible worlds. All the responses have a point, but none of them puts the luck challenge to rest. We can conclude that Franklin's defense of event-causal libertarianism against luck arguments is ultimately unsuccessful.

\section{Acknowledgements}

The research for this article was conducted while I was a research fellow at the University of Leiden and funded by a grant from the Netherlands Organization for Scientific Research (NWO). Earlier versions were presented at a workshop on the theoretical aspects of indeterminism and agency and at a research seminar, both at the University of Utrecht. I would like to thank participants for their helpful comments.

\section{References}

Clarke, R. (2003). Libertarian accounts of free will. Oxford: Oxford University Press. Franklin, C.E. (2011). Farewell to the luck (and Mind) argument. Philosophical Studies, $156,199-230$.

Haji, I. (1999). Indeterminism and Frankfurt-type examples. Philosophical Explorations, 1, $42-58$.

- (2001). Control conundrums: Modest libertarianism, responsibility, and explanation. Pacific Philosophical Quarterly, 82, 178-200.

Hitchcock, C. (1999). Contrastive explanation and the demon of determinism. British Journal of the Philosophy of Science, 50, 585-612. 
Kane, R. (2007). Response to Fischer, Pereboom, and Vargas. In J.M. Fischer, R. Kane, D. Pereboom, \& M. Vargas, Four Views on Free Will (pp. 166-183). Oxford: Blackwell Publishing.

Mele, A.R. (1999). Ultimately responsibility and dumb luck. Social Philosophy and Policy, $16,274-293$.

- (2006). Free will and luck. Oxford: Oxford University Press.

Pereboom, D. (2001). Living without free will. Oxford: Cambridge University Press.

Schlosser, M.E. (2008). Agent-causation and agential control. Philosophical Explorations, $11,3-21$.

- (2010). Agency, ownership, and the standard theory. In J. Aguilar, A. Buckareff, \& K.

Frankish (eds.), New waves in philosophy of action (pp. 13-31).

Basingstoke: Palgrave Macmillan.

van Inwagen, P. (1983). An essay on free will. Oxford: Clarendon Press.

— (2000). Free will remains a mystery. Philosophical Perspectives, 14, 1-19. 